\title{
Tribological behavior of short-cut aramid fiber reinforced SBR elastomers: the effect of fiber orientation
}

\author{
M. Khafidh ${ }^{1,2 *}$, D.J. Schipper ${ }^{1,2}$, M.A. Masen $^{3}$, N. Vleugels ${ }^{1,2}$, J.W.M. \\ Noordermeer ${ }^{1,2}$ \\ ${ }^{1}$ Faculty of Engineering Technology, University of Twente, P.O. Box 217, 7500AE, \\ Enschede, Netherlands. \\ *Email: m.khafidh@utwente.nl \\ Phone: +31534892547; Fax: +31534893471 \\ ${ }^{2}$ Dutch Polymer Institute DPI, P.O. Box 902, 5600A X Eindhoven, Netherlands. \\ ${ }^{3}$ Department of Mechanical Engineering, Imperial College London, Exhibition Road, \\ London, SW7 2AZ, United Kingdom.
}

\begin{abstract}
Elastomeric materials are widely used in daily applications, such as conveyor belts and wiper. Generally, elastomeric materials show poor tribological behavior. Adding fibers to an elastomer is a way to solve this problem. The orientation of the fibers influences the mechanical and tribological behavior of the elastomers. In the present study, the effect of short-cut aramid fiber orientation on the tribological behavior for a Styrene-Butadiene Rubber (SBR) was examined. Three types of compounds which have different fiber orientations were prepared, resulting in normal, transverse and longitudinal orientation to the sliding direction. A contact model of the viscoelastic-anisotropic behaving elastomer was used to calculate the contact area. The friction and wear of the compounds were evaluated using a pin-on-disc tribometer. The results show that the frictional shear stresses of all compounds are nearly the same due to the presence of fibers on the wear track. The normal orientation of fibers shows the most effective way to increase the wear resistance compared to the longitudinal and transverse orientation of the fibers.
\end{abstract}

Keywords: elastomer; fiber orientation; friction; wear.

\section{INTRODUCTION}

Elastomeric materials are used in a wide range of applications, such as tires [1], wiper blades [2] and conveyor belts [3]. Sliding friction often occurs in these applications, which is a major source of frictional losses and wear. For the tire application, the contact between the tire and the road generates slip in the trailing edge of the contact zone [4]. The phenomenon of sliding friction also occurs during strong deceleration. The sliding friction is generated by two different mechanisms: deformation and adhesion [5]. The deformation mechanism is influenced by the properties of the bulk material, while the adhesion mechanism is influenced by the properties of the surface.

An elastomer usually cannot fulfill all of the required properties which are needed in the applications. Adding reinforcing material, such as fibers, is a way to improve the mechanical properties of the elastomers. Several types of fibers have been studied for 
improving the mechanical properties of polymers [6-8] as well as elastomers [9-11]. There is a renewed interest in short 'high performance' fibers being applied in elastomers, because of the recent availability of short-cut aramid fibers. The term "short-cut" means that the length of the fiber is a few millimeters.

The tribological behavior (such as friction and wear) of short-cut aramid fiber reinforced polymers has been investigated in several studies [12-15]. However, the number of studies related to short-cut aramid fiber reinforced elastomers is limited. An important parameter in studying fiber reinforced elastomers is the effect of fiber orientation. When the fibers are randomly oriented, the compound has isotropicviscoelastic behavior. When the fibers are aligned in a certain direction, the compound behaves anisotropic-viscoelastic. The contact of anisotropic-viscoelastic materials has been studied by Rodriguez [16].

In the present study, friction and wear of short-cut aramid fiber reinforced SBR considering the effect of fiber orientation was investigated. Since this study focuses on adhesive friction, a smooth rigid ball with a large radius was used as a counter surface of the elastomeric flat in pin-on-disc tests. Therefore, the effect of deformation friction of the tribo-system can be neglected.

\section{EXPERIMENTAL SET-UP}

\section{Materials}

The studied materials were compounds based on the Styrene-Butadiene Rubber (SBR) from BUNA VSL PBR 4045 HM from Lanxess Leverkusen, Germany. The matrix was reinforced by $15 \mathrm{phr}$ (part per hundred rubber) short aramid fiber (p-phenylene terephthalamide) with an oily standard finish supplied by Teijin Aramid B.V., Arnhem, Netherlands. The length of the aramid fibers is approximately $3 \mathrm{~mm}$, with a diameter of between 10 and $12 \mu \mathrm{m}$. Details of the formulation in phr are described in Table 1. Zinc oxide and stearic acid were from Sigma Aldrich, St. Louis, United States. The silane coupling agent NXT (S-3-(triethoxysilylpropyl)-octanethioate) was obtained by Momentive GE Silicones, Wilton, CT, United States. The sulfur was obtained from Sigma Aldrich, St. Louis, United States. The vulcanization accelerators of n-cyclohexyl-2benzothiazole sulfenamide (CBS) and diphenyl guanidine (DPG) were provided by Flexsys, Brussels, Belgium.

Table 1. Formulation of the compounds.

\begin{tabular}{cc}
\hline Formulation & {$[\mathrm{phr}]$} \\
\hline SBR & 100 \\
NXT & 6 \\
Zinc oxide & 2.5 \\
Stearic acid & 1.5 \\
Aramid fiber & 15 \\
Sulfur & 2.8 \\
CBS & 3.4 \\
DPG & 4 \\
\hline
\end{tabular}


The compounds were prepared using four stages of the mixing procedure based on the optimized procedure in a previous study [17]. At the first stage, the raw SBR was mixed in a Brabender 350S internal mixer. A fixed rotor speed of 110 RPM and an initial temperature of $50^{\circ} \mathrm{C}$ were employed. After 1 minute, the fibers, NXT, zinc oxide and stearic acid were added to the internal mixer. The compound was discharged from the internal mixer after 4 minutes. The second stage was employed to further disperse the fibers. It was done on a Polymix 80T two-roll mill with a nip-width of $\sim 30 \mu \mathrm{m}$ during 6 minutes. At the third stage, the compound was returned to the internal mixer and was mixed with sulfur, CBS and DPG up to a temperature of $100^{\circ} \mathrm{C}$ at $75 \mathrm{RPM}$ for 3 minutes. The fibers in the compound were oriented in the fourth stage, in the two-roll mill with a nip-width of $\sim 50 \mu \mathrm{m}$.

The compounds were vulcanized in a Wickert press WLP 1600 at 100 bar and $160^{\circ} \mathrm{C}$, according to their t90 minutes optimum vulcanization times, as determined with a Rubber Process Analyser (RPA 2000) of Alpha Technologies, following the procedure described in ISO standard 3417. Vulcanized specimens with a thickness of $2 \mathrm{~mm}$ were prepared for tensile and Dynamic Mechanical Analyser (DMA) tests, while vulcanized specimens with a thickness of $5 \mathrm{~mm}$ and a diameter of $50 \mathrm{~mm}$ were prepared for tribometer tests.

\section{Mechanical Characterization}

Mechanical properties are important to analyze the tribological behavior of the compounds. Tensile tests of all vulcanized compounds were performed on an Instron 3343 series tensile tester with a force transducer with a capacity of $1000 \mathrm{~N}$, according to ISO 37 and a crosshead speed of $500 \mathrm{~mm} / \mathrm{min}$. A Dynamic Mechanical Analyser (DMA) was used to determine the dynamic properties of the compounds. Creep compliances of the compounds were determined using the Metravib Viscoanalyser DMA+150 at constant stress and ambient temperature.

\section{Tribometer Tests}

A pin-on-disc tribometer was used for measuring the friction force of the compounds, see Figure 2(a). Three types of fiber orientation were studied, i.e., normal, transverse and longitudinal orientation. Normal orientation means that the fibers are oriented perpendicularly to the compound surface. Transverse orientation means that the fibers are oriented perpendicularly to the sliding direction. While, longitudinal orientation means that the fibers are oriented in the sliding direction, see Figure 2(b-d).

The radius of the rigid spherical counter surface was $17.5 \mathrm{~mm}$. The operating conditions of the experiments were the same for all compounds, i.e., a velocity of $0.2 \mathrm{~m} / \mathrm{s}$ and mean contact pressure of $0.2 \mathrm{MPa}$. The experiments were performed at room temperature. The wear volume of each compound was measured using a Keyence Confocal Microscopy VK 9700. Based on the average measured wear volume, the specific wear rate can be calculated using the Archard's equation [18]. The wear surface and the wear particles of each compound were observed using the Keyence VHX-5000 microscope and the Jeol JSM 6400 Scanning Electron Microscope (SEM), respectively. 
(a)

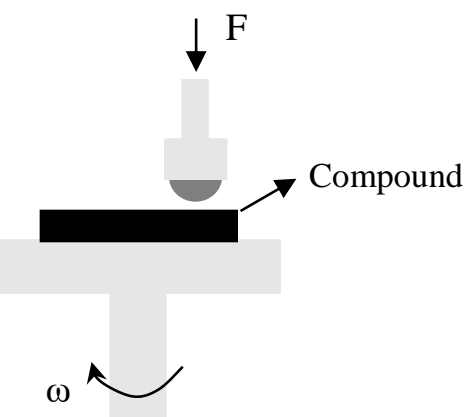

(c)

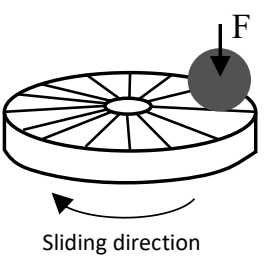

(b)

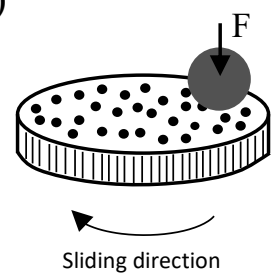

(d)

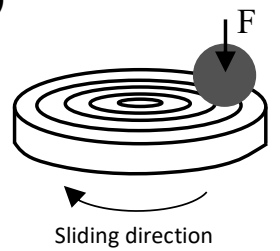

Figure 2. (a) Pin-on-disc tribometer, schematically, (b,c,d) the compounds containing fibers in normal, transverse and longitudinal direction.

\section{RESULTS AND DISCUSSION}

\section{Mechanical Properties of the Compounds}

The tensile tests results of the compounds in several orientations can be seen in Figure 3. The compound which is reinforced in random orientation has a steeper curve compared to those in $x$ direction (meaning that the fibers aligned perpendicularly to the applied force). Whereas, the compound which is reinforced in $z$ direction (meaning that the fibers aligned longitudinally to the applied force) gives the steepest curve. These results indicate that the random reinforcement gives a stiffer compound compared to the reinforcement in $x$ direction. Whereas, the reinforcement in $z$ direction gives the stiffest compound.

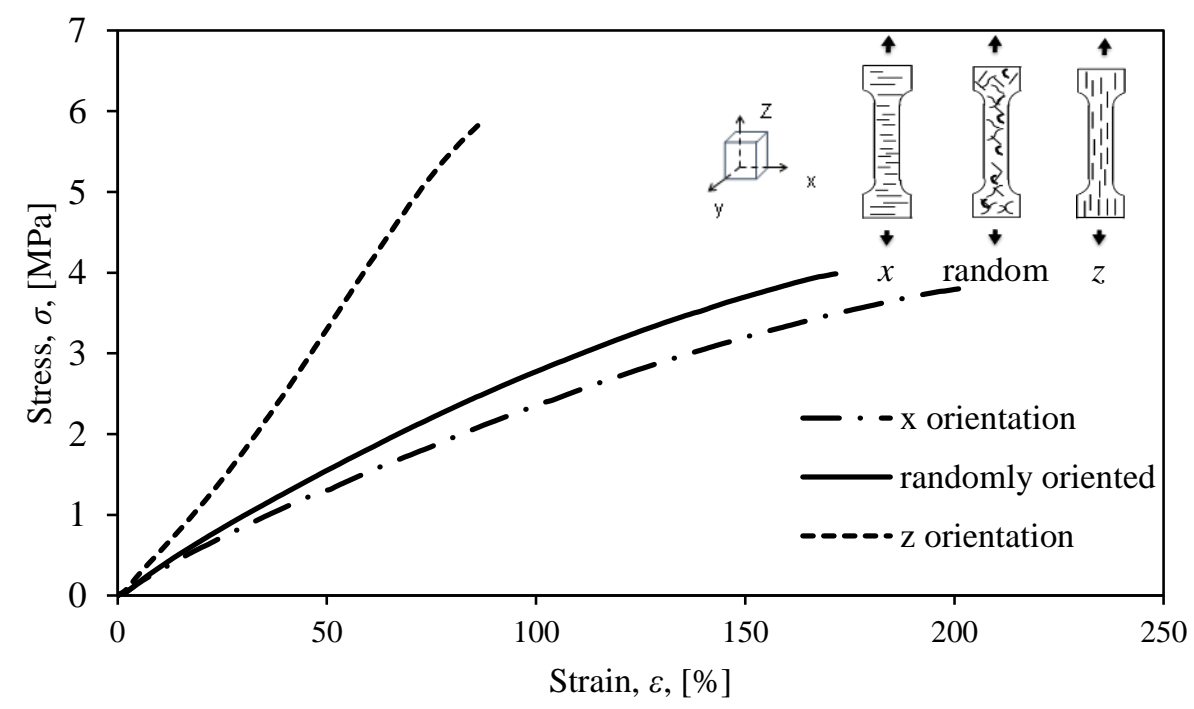

Figure 3. Stress-strain behavior of the compounds. 
The experimental results of creep compliances can be seen in Figure 4. The creep compliance of the compound containing fibers in random direction is lower than of the compound which is reinforced in $x$ direction. While the compound containing fibers in $z$ direction shows the lowest creep compliance because it has stiffer properties compared to the other compounds, see Figure 3. The experimental results of creep compliances can be fitted using a series of discrete exponential terms given by [19]:

$$
\phi(t)=\phi_{r}-\sum_{i=1}^{3} \phi_{i} \exp \left(\frac{-t}{\lambda_{i}}\right)
$$

where $\phi_{r}$ indicates the creep at a fully relaxed state, $t$ indicates time and $\lambda_{i}$ indicates the retardation times. As can be seen in Figure 4, the creep compliances of the compounds are very well described by the equation. The parameter values of the fit equation can be found in Table 2 for all compounds.

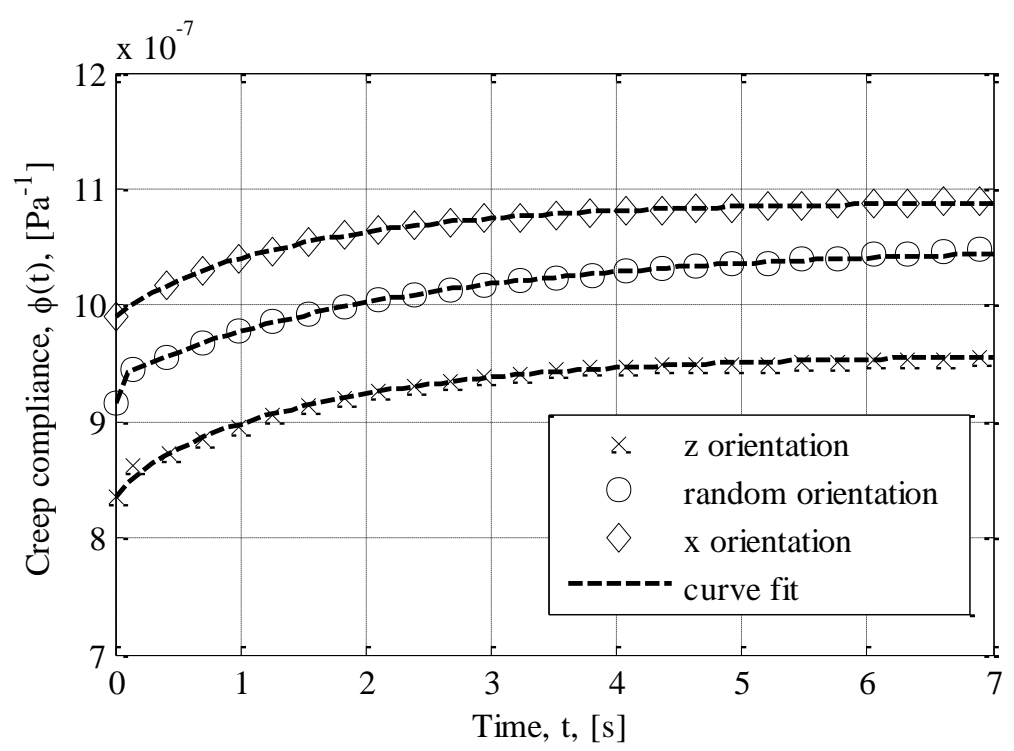

Figure 4. The experimental and curve fit results of creep compliances for the different orientations of fibers.

Table 2. Parameter values of fit equation.

\begin{tabular}{cccc}
\hline & $x$ orientation & random & $z$ orientation \\
\hline$\phi_{r}\left[\mathrm{~Pa}^{-1}\right]$ & $1.09 \times 10^{-06}$ & $1.05 \times 10^{-06}$ & $0.96 \times 10^{-06}$ \\
$\phi_{1}\left[\mathrm{~Pa}^{-1}\right]$ & $4.31 \times 10^{-09}$ & $2.13 \times 10^{-08}$ & $9.77 \times 10^{-09}$ \\
$\phi_{2}\left[\mathrm{~Pa}^{-1}\right]$ & $1.13 \times 10^{-08}$ & $2.27 \times 10^{-08}$ & $2.14 \times 10^{-08}$ \\
$\phi_{3}\left[\mathrm{~Pa}^{-1}\right]$ & $8.23 \times 10^{-08}$ & $9.05 \times 10^{-08}$ & $8.18 \times 10^{-08}$ \\
$\lambda_{1}[\mathrm{~s}]$ & 0.302 & 0.009 & 0.138 \\
$\lambda_{2}[\mathrm{~s}]$ & 0.808 & 1.362 & 0.701 \\
$\lambda_{3}[\mathrm{~s}]$ & 1.687 & 2.730 & 1.947 \\
\hline
\end{tabular}




\section{The Contact Area of the Anisotropic-viscoelastic Compounds}

The contact area of the elastomeric materials depends on the contact time due to their viscoelastic behavior. Therefore, the contact areas of elastomeric materials are different in static and sliding conditions [20]. Anisotropic behavior of the materials is another complication in studying the contact area of elastomeric materials. Adding short-cut fibers at a certain orientation in the elastomer will change the behavior of the compound where it will become anisotropic-viscoelastic. Fiber reinforced elastomers with an anisotropic-viscoelastic behavior result in a time-dependent deformation and different mechanical properties in every direction. The contact model of Rodriguez was used to calculate the contact area of an anisotropic-viscoelastic compound in contact with a counter surface. The equations are given by [16]:

$$
a_{x}(t)=\left(\frac{3 R F_{N}}{4}\right)^{1 / 3}\left[I_{1} \bar{\phi}(t)\right]^{1 / 3} \quad \text { and } \quad a_{y}(t)=\left(\frac{3 R F_{N}}{4}\right)^{1 / 3}\left(\frac{I_{2}^{1 / 2}}{I_{1}^{1 / 6}}\right)[\bar{\phi}(t)]^{1 / 3}
$$

where $a_{x}$ and $a_{y}$ are the radii of the contact area in $x$ and $y$ direction, respectively. $R$ is the radius of the spherical counter surface, $F$ is the normal force and $\bar{\phi}$ is the normalized creep compliance. $I_{1}$ and $I_{2}$ are the numerical solutions of two contour integrals, dependent on nine material properties $\left(E_{x}, E_{y}, E_{z}, G_{x y}, G_{x z}, G_{y z}, v_{x y}, v_{x z}, v_{y z}\right) . E$ is the elastic modulus, $G$ is the shear modulus and $v$ is Poisson's ratio. For the detailed calculation procedure, the reader is referred to [15]. From the tensile tests, the average elastic modulus for the longitudinally and transversely oriented compounds are $E_{x}=3.36 \pm 0.21 \mathrm{MPa}$ and $E_{y}=E_{z}$ $=2.23 \pm 0.21 \mathrm{MPa}$. While the average elastic modulus for the normally oriented compound are $E_{x}=E_{y}=2.23 \pm 0.21 \mathrm{MPa}$ and $E_{z}=3.36 \pm 0.21 \mathrm{MPa}$. The creep compliances of the compounds can be obtained by putting the parameter values of Table 2 into Eq. (1). The shear modulus of the compounds were calculated using Eq. (3), assuming the compound is a quasi-incompressible material (Poisson's ratio $\sim 0.5$ ), common for elastomer.

$$
G=\frac{E}{2(1+v)}
$$

The calculation results are given in Figure 5. It shows that the contact area increases with time. After approximately 6 seconds, the contact areas become constant. The compound reinforced in normal direction has the smallest contact area, while the longitudinal and transverse ones show the largest contact area. The theory of Hertz is in accordance with the randomly oriented compound at a long-time scale.

The contact area of a viscoelastic material will be influenced with time. Therefore, the contact time between the elastomer and the counter surface has to be defined to calculate the contact area of the compounds at the velocity used in the tests. In the present study, the contact time between the counter surface and the elastomer was estimated as the ratio of the diameter of contact patch in the direction of sliding and the velocity of the tests. For example, by using Eq. (2), the diameter of contact between the counter surface and the longitudinally oriented compound in the direction of sliding is $2.7 \times 10^{-3} \mathrm{~m}$. Therefore, the contact time between them at a velocity of $0.2 \mathrm{~m} / \mathrm{s}$ is 0.013 seconds. Finally, the contact area of this compound at a velocity of $0.2 \mathrm{~m} / \mathrm{s}$ is $22.46 \times 10^{-6} \mathrm{~m}^{2}$ (see 
inset Figure 5). Similarly, the contact area at a velocity of $0.2 \mathrm{~m} / \mathrm{s}$ for all compounds can be calculated following the same procedure. The calculated contact areas for the normally and transversely oriented compounds are $12.22 \times 10^{-6} \mathrm{~m}^{2}$ and $22.49 \times 10^{-6} \mathrm{~m}^{2}$, respectively.

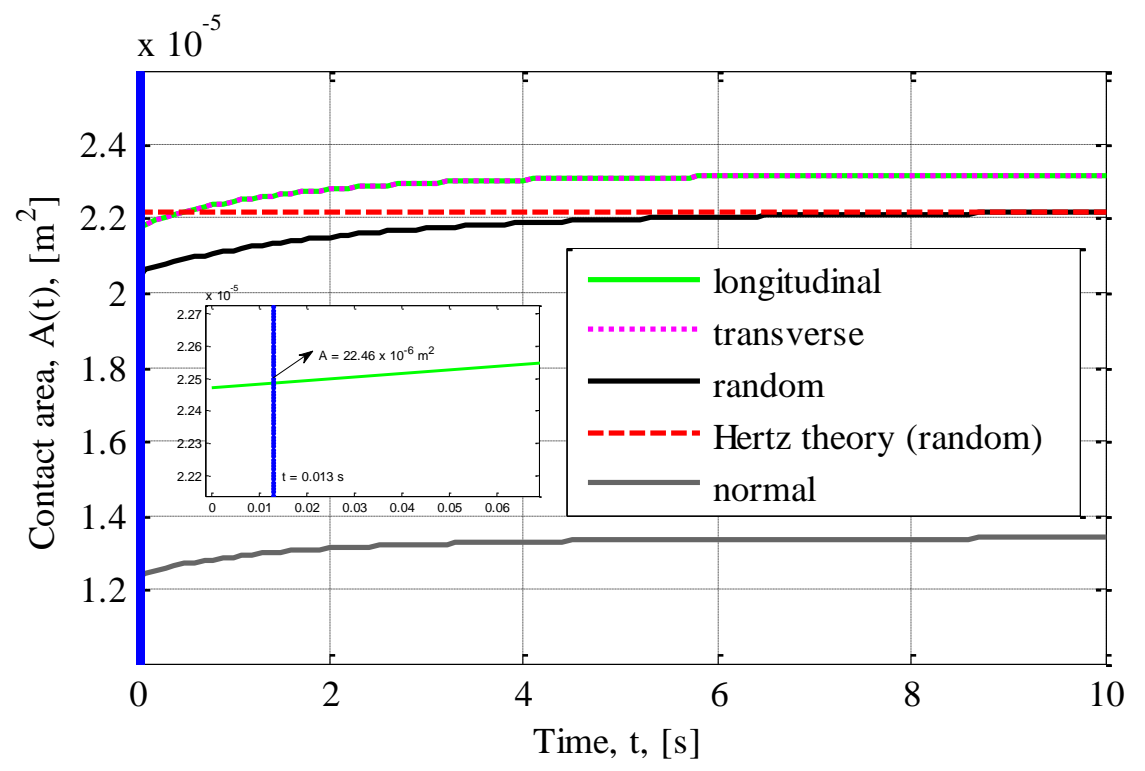

Figure 5. The contact areas of the compounds for several reinforcement directions as a function of time.

\section{Friction}

The effect of fiber reinforcement direction on friction is discussed in this section. The friction forces for all compounds as a function of sliding distance are plotted in Figure 6. The results show that the friction force decreases during the running-in process. After a sliding distance of approximately $500 \mathrm{~m}$, the friction forces show constant values. The tribometer tests were stopped at a sliding distance of $3770 \mathrm{~m}$. The average friction forces at the steady state phase are $1.3 \pm 0.03,2.1 \pm 0.07$ and $2.3 \pm 0.03 \mathrm{~N}$ for the compounds reinforced in normal, transverse and longitudinal direction, respectively.

The total friction is the resultant of friction caused by deformation and adhesive friction [5]. A wet friction test was performed to distinguish both of them. The compounds were wetted by a very thin layer of oil (Ondina 927 with a dynamic viscosity of $78 \mathrm{~m} \mathrm{Pa.s}$ at $20^{\circ} \mathrm{C}$ ), hence the lubricated tribo-system remains in the boundary lubrication regime [21]. Therefore, the influence of the adhesion mechanism is excluded and the deformation effect will be dominant. The friction forces in wet condition reduced drastically to approximately one-fifth of the dry condition for all compounds. Based on these results, it is concluded that the adhesive friction is the dominant mechanism in the total friction measured under dry conditions (Figure 6). As a result, the deformation friction was neglected in this study.

The adhesive friction will be greatly influenced by the contact area between the counter surface and the elastomer, the relation of them can be described as:

$$
F_{a d h}=A \tau
$$


where $F_{a d h}$ is the adhesive friction force, $A$ is the contact area, and $\tau$ is the frictional shear stress.

The frictional shear stresses of each compound can be calculated using Eq. (4). The friction forces are obtained from the experiments, while the contact areas are obtained from the calculations. The results show that the frictional shear stresses are nearly the same for all the compounds in the steady state phase, i.e., $\sim 0.1 \mathrm{MPa}$. This can be explained by the presence of fibers on the wear surface at the end of the tests, see Figure 8. The fibers are present for all compounds and they align in the sliding direction. The frictional shear stresses are controlled by the existence of the fibers on the wear surface. Since the frictional shear stresses are nearly the same for all the compounds, the contact area is the important parameter that influences the friction force.

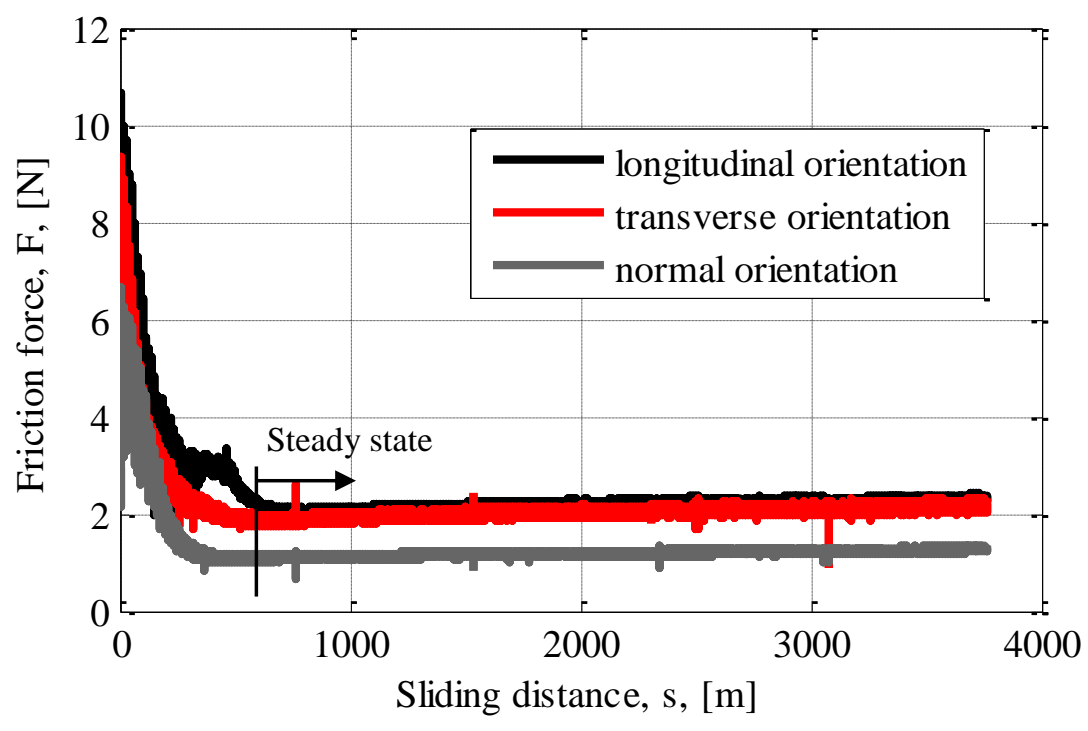

Figure 6. Friction forces as a function of sliding distance for the compounds in this study.

\section{Wear}

The specific wear rates of the compounds can be seen in Figure 7. It shows that the compounds containing fibers in the normal direction to the contact give the lowest specific wear rate. While the specific wear rate of the compounds containing fibers in the longitudinal direction gives a slightly higher compared to those compounds containing fibers in the transverse direction.

When the fibers are aligned in the normal direction, the fracture of fibers will require a tensile loading due to a mechanical pulling action at the interface. However, the pull-out mechanism occurs with difficulty since the compound containing normally oriented fibers are deeply embedded in the matrix and offer a great resistance to detachment. Moreover, the lateral deformation will be constrained by the presence of neighboring fibers. Therefore, only a small part of the fibers are detached from the matrix. Figure 8 shows that the compound containing fibers in normal direction has shorter fibers on the wear surface compared to that in the other orientations. As a result, the compound containing fibers in normal direction shows the lowest specific wear rate. This result is consistent with some of the work reported in the previous studies [22-26]. 


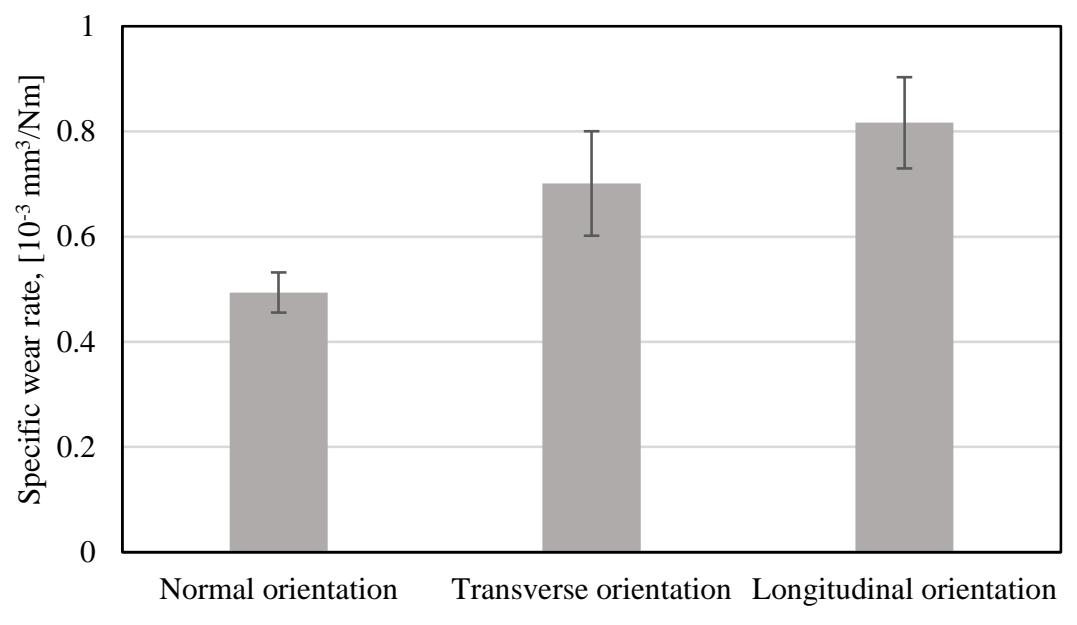

Figure 7. Specific wear rate of the compounds for the several reinforcement directions.

When the fibers are aligned parallel to the surface compound, i.e., longitudinally and transversely oriented samples, the fiber pull-out occur easier than for normal orientation. Therefore, the specific wear rates of the compounds which are reinforced in longitudinal and transverse direction are higher than those compounds which are reinforced in normal direction. The difference between the transverse and longitudinal orientation is not significant. Several studies concluded that the compounds containing transversely oriented fibers show larger wear compared to the compounds containing longitudinally oriented fibers [22, 23]. However, other studies show opposite results [24-26].
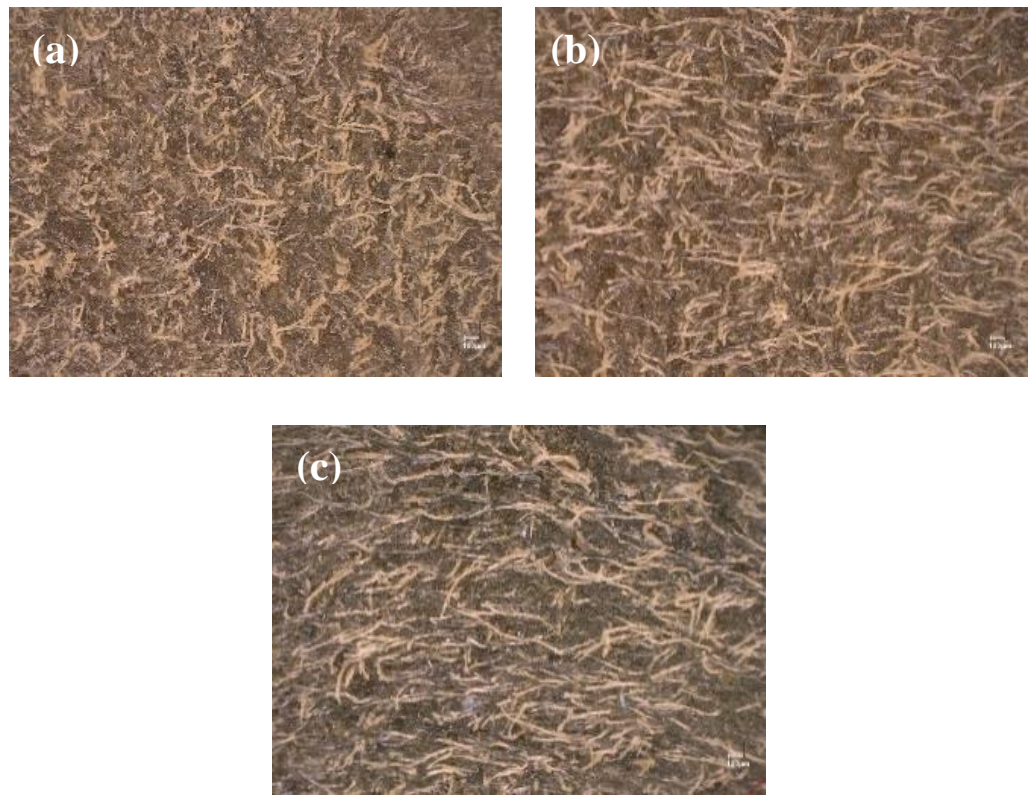

Figure 8. Wear surfaces of the compounds containing fibers in: (a) normal direction, (b) transverse direction and (c) longitudinal direction. 
The wear particles of the compounds are given in Figure 9. It shows that they are powdery and "dust like," see Figure 9a. When a high magnification is performed, relatively long fibers are found in the wear particles, see Figure 9b. It indicates that fibers are pulled-out from the elastomer matrix during sliding contact.
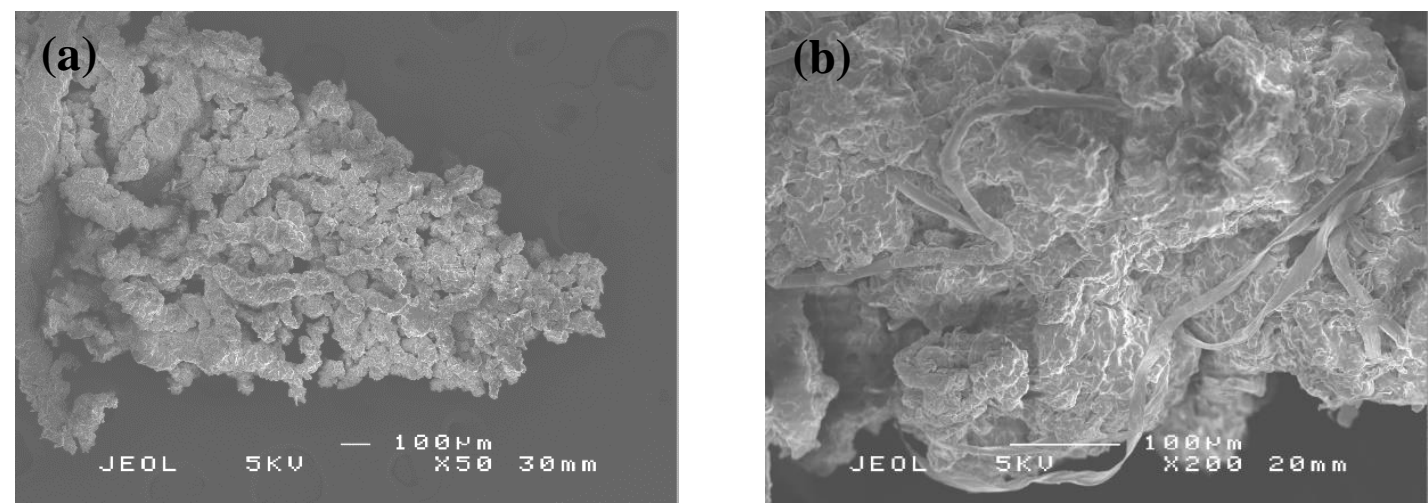

Figure 9. Wear particle of the compounds; (a) low magnification (b) high magnification.

\section{CONCLUSIONS}

The effect of short-cut aramid fiber orientation of fiber reinforced elastomers with respect to the tribological behavior has been studied. The conclusions can be summarized as follows:

1. The fiber reinforcement in random direction gives a stiffer compound compared to the fiber reinforcement in the perpendicular to the loading direction. While the fiber reinforcement in the loading direction gives the stiffest compound.

2. The contact area of the compound containing fibers in the longitudinal direction is nearly the same as the transverse direction one. While the contact area of the compound containing fibers in the normal direction shows the smallest contact area.

3. At the end of the tests, the fibers are oriented in the sliding direction. Therefore, the frictional shear stresses of all the reinforced compounds are nearly the same. The contact area becomes the major factor that influences the friction force.

4. The fiber reinforcement in the normal direction to the sliding contact gives the greatest resistance of the fiber detachment. Therefore, the lowest wear can be found for fiber reinforced compounds in which the fibers are oriented in the normal direction.

\section{ACKNOWLEDGMENTS}

This research forms part of the Research Programme of the Dutch Polymer Institute DPI, Project \#782.

\section{REFERENCES}

[1] Lorenz B, Oh YR, Nam SK, Jeon SH, Persson BN. Rubber friction on road surfaces: Experiment and theory for low sliding speeds. J Chem Phys. 2015; 142: 194701. 
[2] Bódai G, Goda TJ. Friction Force Measurement at Windscreen Wiper/Glass Contact. Tribology Letters. 2012; 45: 515-23.

[3] Zhao LH, Wei XB, Li XG. The Analysis on the Tribological Properties of CR/EPDM Blends with Chrome-Plated Steel under Dry Sliding. Advanced Materials Research. 2013; 774: 99-102.

[4] Mané Z, Loubet J-L, Guerret C, Guy L, Sanseau O, Odoni L, Vanel L, Long DR, Sotta P. A new rotary tribometer to study the wear of reinforced rubber materials. Wear. 2013; 306: 149-60.

[5] Bhushan B. Principles and applications of tribology. New York: John Wiley \& Sons; 2013.

[6] Tezara C, Siregar JP, Lim H, Fauzi F, Yazdi MH, Moey L, Lim J. Factors that affect the mechanical properties of kenaf fiber reinforced polymer: A review. Journal of Mechanical Engineering and Sciences. 2016; 10: 2159-75.

[7] Sepe R, Bollino F, Boccarusso L, Caputo F. Influence of chemical treatments on mechanical properties of hemp fiber reinforced composites. Composites Part B: Engineering. 2018; 133: 210-7.

[8] Ahmed S, Ahsan A, Hasan M. Physico-mechanical properties of coir and jute fibre reinforced hybrid polyethylene composites. International Journal of Automotive \& Mechanical Engineering. 2017; 14: 3927-37.

[9] Hariwongsanupab N, Thanawan S, Amornsakchai T, Vallat MF, Mougin K. Improving the mechanical properties of short pineapple leaf fiber reinforced natural rubber by blending with acrylonitrile butadiene rubber. Polymer Testing. 2017; 57: 94-100.

[10] Shadrinov NV, Nartakhova SI. Structure and properties of nitrile-butadiene rubber filled with carbon and basalt fibers. Inorganic Materials: Applied Research. 2017; 8: 140-4.

[11] Favre A, Fotsing ER, Levesque M, Ruiz E. Comparative study of fiber-reinforced elastomer composites subjected to accelerated aging in water. Journal of Elastomers and Plastics. 2015; 47: 719-37.

[12] Wang L-Q, Jia X-M, Cui L, Chen G-C. Effect of aramid fiber and ZnO nanoparticles on friction and wear of PTFE composites in dry and LN2 conditions. Tribology Transactions. 2008; 52: 59-65.

[13] Lv M, Zheng F, Wang Q, Wang T, Liang Y. Friction and wear behaviors of carbon and aramid fibers reinforced polyimide composites in simulated space environment. Tribology International. 2015; 92: 246-54.

[14] Kukureka SN, Hooke CJ, Rao M, Liao P, Chen YK. The effect of fibre reinforcement on the friction and wear of polyamide 66 under dry rolling-sliding contact. Tribology International. 1999; 32: 107-16.

[15] Rodriguez NV. Contact and friction in systems with fibre reinforced elastomers. $\mathrm{PhD}$ thesis. Enschede, The Netherlands. University of Twente. 2012.

[16] Rodriguez NV, Masen MA, Schipper DJ. A contact model for orthotropicviscoelastic materials. International Journal of Mechanical Sciences. 2013; 74: 91-98.

[17] Vleugels N. Short fibre-reinforced elastomeric composites, fundamental routes towards improvement of the interfacial interaction of short-cut aramid fibres in a SBR compound, to improve friction and wear properties. PhD Thesis. Enschede, The Netherlands. University of Twente. 2017. 
[18] Archard JF, Hirst W. The wear of metals under unlubricated conditions. Proceedings of the Royal Society of London. 1956; A-236: 397-410.

[19] Ferry JD. Viscoelastic properties of polymers, $2^{\text {nd }}$ ed. New York: John Wiley \& Sons; 1980.

[20] Khafidh M, Rodriguez NV, Masen MA, Schipper DJ. The dynamic contact area of elastomers at different velocities. Tribology - Materials, Surfaces \& Interfaces. 2016; 10: 70-3.

[21] Mokhtari M, Schipper DJ, Vleugels N, Noordermeer JW. Existence of a tribomodified surface layer on SBR elastomers: Balance between formation and wear of the modified layer. Tribology letters. 2015; 58: 22.

[22] Wada N, Uchiyama Y. Friction and wear of short-fibre-reinforced rubber composites under various sliding speeds and loads. Wear. 1993; 162: 930-8.

[23] Nak-Ho S, Suh NP. Effect of fiber orientation on friction and wear of fiber reinforced polymeric composites. Wear. 1979; 53: 129-41.

[24] Chand N, Dwivedi U. Influence of fiber orientation on high stress wear behavior of sisal fiber-reinforced epoxy composites. Polymer composites. 2007;28:437-41.

[25] Lancaster J. The effect of carbon fibre reinforcement on the friction and wear of polymers. Journal of Physics D: Applied Physics. 1968; 1: 549.

[26] Shim HH, Kwon OK, Youn JR. Effects of fiber orientation and humidity on friction and wear properties of graphite fiber composites. Wear. 1992;157:141-9. 